\title{
2D double aeolotropic conductive Janus pellicle with multi-functionality then derived 3D dual-wall Janus-type tube
}

\author{
H. N. Qi, Q. L. Ma, Y. R. Xie, Y. Song, J. Tian, W. S. Yu, X. T. Dong ${ }^{*}$, D. Li, G. X. Liu, J. X. Wang
}

Key Laboratory of Applied Chemistry and Nanotechnology at Universities of Jilin Province, Changchun University of Science and Technology, 130022 Changchun, China

Received 2 June 2019; accepted in revised form 3 August 2019

\begin{abstract}
Two-dimensional (2D) bilayer Janus pellicle (denoted as BJP) of concurrent double aeolotropic electrical conduction, superparamagnetism and luminescence is designed and constructed via electrospinning by using one-dimensional (1D) nanofibers and Janus nanoribbons as constructive units. The BJP comprises top-down two layers tightly bonded together. The top layer is a left-right structured Janus film which consists of Janus nanoribbons array as left and right side, and further, arrangement orientations of Janus nanoribbons in the two sides are perpendicular, leading to double aeolotropic conduction, and the conduction ratio reaches $10^{8}$ times. The down layer is a non-array luminescent film made of nanofibers. Under the excitation by 291 and $294 \mathrm{~nm}$ light, red luminescence of the left side of the top layer and green luminescence of down layer in BJP are respectively achieved. The maximum saturation magnetization of the top layer can reach 21.45 (emu/g). By rolling the 2D BJP into the tube respectively with the ways of rolling from left to right or from up to down, three-dimensional (3D) dual-wall Janus-type tube with the Janus-type tube as outer or inner and the homogeneous tube as inner or outer is obtained.
\end{abstract}

Keywords: nanomaterials, aeolotropic conductive pellicle, luminescence, superparamagnetism, three-dimensional dualwall Janus tube

\section{Introduction}

The Janus pellicle is a novel pellicle with asymmetric properties on each part [1]. As one of the pellicle materials, Janus pellicles [2-6] have been widely used in electrical engineering and biology due to their special structural characteristics. For example, a PVFM-based Janus pellicle is used for a highly durable Li- $\mathrm{O}_{2}$ battery [7], a bionic Janus composite pellicle is used for a smart response actuator [8], and a hydrophobic-hydrophilic Janus pellicle is used for the mist collector [9]. Yang et al. [10], concluded that the Janus pellicle can be top-bottomed, it can usually be divided into three categories: $\mathrm{A}$ on $\mathrm{B}$ or $\mathrm{B}$ on $\mathrm{A}$, $\mathrm{A}$ and $\mathrm{B}, \mathrm{A}$ to $\mathrm{B}$. Xiong et al. [11], prepared a S-Mo-Se transition metal disulfide based on the Janus structure. The MoSeS film always spontaneously curls at a constant temperature and pressure and tends to be chair-oriented. When the size of the film exceeds $30 \mathrm{~nm}$, it curls into a tubular shape spontaneously. Janus material refers to two chemical constituents which have a distinct separate structure in the same system. The particular Janus structure can reduce the pernicious effects of varying materials by limiting them in their respective fields at the microlevel. For example, for electrically conductive-luminescent-magnetic multifunctional materials, according to the reports [12-14], when conductive, luminescent and magnetic materials are directly blended together, unfavorable interferences will occur. Using Janus structural materials to separate different materials can effectively reduce its adverse effects.

With the development of science and technology, aeolotropic electrically conductive materials $[15,16]$ have become one of the research hotspots due to 
their unique conductive properties. Aeolotropic conductive films (ACFs) [17-20] with exceptive structure have important applications in some electronic components [21], photoelectric switch [22], sensors [23] and other fields. There have been several types of ACFs reported. The films that conduct electricity along the thickness direction of the film are known as type IACFs [24], and films that conduct in two perpendicular directions on the surface are defined as type II ACFs [25]. Based on the reports, the type II aeolotropic conductive materials are still in the stage of laboratory exploration. Researchers are striving to develop a novel structure of aeolotropic conductive pellicle to achieve electrical conduction in specific directions of the film surface and multifunctionality to meet the needs of the rapid development of electronics and nanotechnology. The conductive materials are usually prepared by heat pressing [26], ultrasonic welding [27] or electrospinning [28-35]. Among these techniques, electrospinning is a simple and economical method to prepare nano-materials with various properties due to its convenient preparation process and good repeatability. Side-by-side electrospinning [36-38], as a kind of useful electrospinning technology, is a good method to prepare materials with Janus structure. Janus materials prepared by this electrospinning are widely used in drug release, oil-water separation, and other fields.

In this work, we innovatively design a new type of ACF, called as two-dimensional (2D) bilayer Janus pellicle (denoted as BJP). Microscopically, we use the Janus nanoribbon as the constructional conductive unit to prepare the aeolotropic conductive pellicle. The Janus nanoribbon consists of conductive part and insulating-luminescent or insulating-superparamagnetic part to ensure high aeolotropic conductivity of the composite pellicle. Macroscopically, the aeolotropic conductive pellicle is further designed as a Janus pellicle with the left-right structure to realize double aeolotropic conduction. In order to concurrently realize the integration of the three functions of luminescence-conduction-superparamagnetism in a single material and increase the mechanical properties of the pellicle, we introduce luminescent nanofibers into ACF as the second layer. To achieve the above-designed ideas, herein, we use electrospinning to prepare the BJP, the top layer is a left-right structured Janus film using Janus nanoribbon as the constructional unit with synchronous double electrically conductive aeolotropism, luminescent and superparamagnetic multi-functionality, the down layer is a non-array luminescent film (marked as NLF) with nanofiber as the constructional unit. We utilized $\mathrm{Fe}_{3} \mathrm{O}_{4}$ nanoparticles (NPs) $[39,40]$ as a magnetic material, polyaniline (PANI) $[41,42]$ as a conductive material, and rare-earth complexes $\mathrm{Eu}(\mathrm{BA})_{3}$ phen $[43,44]$ and $\mathrm{Tb}(\mathrm{BA})_{3}$ phen $[45,13]$ as light-emitting materials. Finally, three-dimensional (3D) Janus-type tubes can be conveniently obtained by rolling the BJP via various strategies, thus we successfully realize the transition from 1D nanofibers and Janus nanoribbons to $2 \mathrm{D}$ double aeolotropic conductive bilayer Janus pellicle then to 3D Janus-type tubes. The specially designed and manufactured 2D bilayer Janus pellicle and the 3D Janus-type tube have potential applications in the simultaneous adsorption of different heavy metals, oil-water separation, tissue cell growth, electromagnetic interference shielding and electronic industry.

\section{Materials and methods \\ 2.1. Chemicals}

$\mathrm{NH}_{4} \mathrm{NO}_{3}$, polyethylene glycol (PEG, $\left.M_{\mathrm{w}}=20000\right)$, $\mathrm{FeCl}_{3} \cdot 6 \mathrm{H}_{2} \mathrm{O}$, oleic acid (OA), $\mathrm{CHCl}_{3}$, (1S)-(+)-10camphorsulfonic acid (CSA), $\mathrm{FeSO}_{4} \cdot 7 \mathrm{H}_{2} \mathrm{O}$, methylmethacrylate (MMA), $N, N$-dimethylformamide (DMF), $\mathrm{NH}_{3} \cdot \mathrm{H}_{2} \mathrm{O}$, ammonium persulfate (APS), benzoylperoxide (BPO), $\mathrm{Tb}_{4} \mathrm{O}_{7}(99.99 \%)$, benzoic acid (BA), $\mathrm{Eu}_{2} \mathrm{O}_{3}$ (99.99 \%), 1,10-phenanthroline (phen), anhydrous ethanol alcohol were used, and all of the chemicals were of analytic grade and purchased from Aladdin reagent co. LTD, Shanghai, China. PMMA, $\mathrm{Eu}(\mathrm{BA})_{3}$ phen, $\mathrm{Tb}(\mathrm{BA})_{3}$ phen and $\mathrm{Fe}_{3} \mathrm{O}_{4}$ NPs were prepared according to the papers [14, 46, 47].

\subsection{Projecting of constructional units of 2D bilayer Janus pellicle}

The schematic diagram of the assembled 2D bilayer Janus pellicle (BJP) of $\left\{\left[\mathrm{Eu}(\mathrm{BA})_{3}\right.\right.$ phen/polymethylmethacrylate (PMMA)]//[polyaniline (PANI)/ PMMA $]\} \perp\left\{\left[\mathrm{Fe}_{3} \mathrm{O}_{4} / \mathrm{PMMA}\right] / /[\mathrm{PANI} / \mathrm{PMMA}]\right\}$ Janus nanoribbons array film and $\left[\mathrm{Tb}(\mathrm{BA})_{3}\right.$ phen/ PMMA] nanofibers non-array film was shown in Figure 1. The BJP consists of top-down two layers: the top layer is a left-right structured Janus film defined as LRJF (Figure 1a) with the left and right structure and the down layer is a non-array luminescent film (NLF, Figure 1b). As shown in Figure 1a, the LRJF is the left and right structure with the left side (named as L-LRJF) comprised $\left[\mathrm{Eu}(\mathrm{BA})_{3}\right.$ phen/(PMMA)]// 


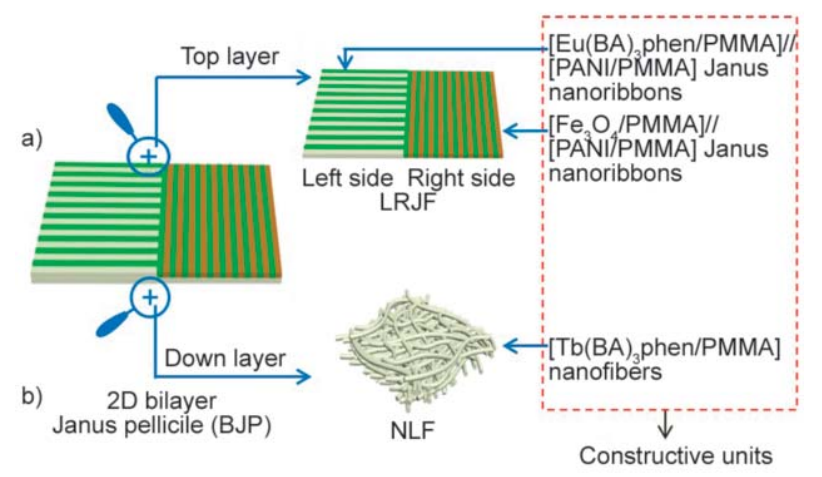

Conductive area Luminescent area Superparamagnetic area

Figure 1. Schematic diagram of structure of 2D bilayer Janus pellicle (BJP), (a, up layer) left-right structured Janus film (LRJF) and (b, down layer) nonarray luminescent film (NLF).

[PANI/PMMA] Janus nanoribbons and the right side (denoted as R-LRJF) composed of $\left[\mathrm{Fe}_{3} \mathrm{O}_{4} / \mathrm{PMMA}\right] / /$ [PANI/PMMA] Janus nanoribbons. One part of the single $\left[\mathrm{Eu}(\mathrm{BA})_{3}\right.$ phen/PMMA]/[PANI/ PMMA] Janus nanoribbon is composed of rare earth emitting complex and PMMA, and the other part consists of PANI and PMMA. As for the $\left[\mathrm{Fe}_{3} \mathrm{O}_{4} / \mathrm{PMMA}\right] / /[\mathrm{PANI} /$ PMMA] Janus nanoribbon, one part is made up of $\mathrm{Fe}_{3} \mathrm{O}_{4}$ and PMMA, and another part contains PANI and PMMA. This special structure of the Janus nanoribbon provides two mutually independent regions that respectively contain luminescent and conductive materials or superparamagnetism and conductive materials, and thus, the two kinds of materials are separated and concurrently assembled into one strip of Janus nanoribbon. Figure $1 \mathrm{~b}$ shows the NLF, which composed of [Tb(BA $)_{3}$ phen/ PMMA] nanofibers. The LRJF and NLF also form two independent regions, therefore, the luminescent material, the conductive material and the magnetic material are mutually independent and simultaneously assembled into one specimen (BJP).

\subsection{Construction of spinning dopes}

To fabricate $\mathrm{Fe}_{3} \mathrm{O}_{4} / \mathrm{PMMA}$ as the insulating part of the Janus nanoribbon, $\mathrm{Fe}_{3} \mathrm{O}_{4} \mathrm{NPs}$ were dispersed into a mixed solvent of $\mathrm{CHCl}_{3}$ and DMF under ultrasonic for 25 min and then PMMA was added into the suspension under mechanical agitation for $18 \mathrm{~h}$. The above-mentioned mixture was called as the spinning dope $\left(\mathrm{S}_{\mathrm{a}}\right)$ I and Table 1 summarized the real components.

PANI/PMMA was used as the conductive material in the conductive part of the Janus nanoribbon, the processes of preparing the spinning dope containing PANI was as follows. CSA and ANI were dispersed in the mixture dope of $\mathrm{CHCl}_{3}$ and DMF with different ANI/PMMA percentages, and the dope was stirred at ambient temperature for $12 \mathrm{~h}$ (defined as dope A), meanwhile APS was dispersed into the DMF and stirred for $1 \mathrm{~h}$ (defined as dope B). Dope A and dope $\mathrm{B}$ were refrigerated for $25 \mathrm{~min}$ at $0{ }^{\circ} \mathrm{C}$. Dope $\mathrm{B}$ was slowly poured into dope $\mathrm{A}$ and then stirred in an ice-water bath for $3.5 \mathrm{~h}$. Finally, the reaction system was kept at $0{ }^{\circ} \mathrm{C}$ for $36 \mathrm{~h}$ to obtain dope II, and Table 2 summed up the actual components of spinning dope II $\left(\mathrm{S}_{\mathrm{b}}\right)$.

According to the references [48-50], when $\mathrm{Eu}(\mathrm{BA})_{3}$ phen was mixed with PMMA and used as the spinning dope to prepare the insulating-red luminescent part of the Janus nanoribbon, the optimum doping percent of $\mathrm{Eu}(\mathrm{BA})_{3}$ phen in PMMA was $15 \%$, and as for the $\mathrm{Tb}(\mathrm{BA})_{3}$ phen/PMMA nanofibers which used as the down layer of the BJP, the optimal doping

Table 1. Compositions of the spinning dope I.

\begin{tabular}{|c|c|c|c|c|c|}
\hline Spinning dope I & $\begin{array}{c}\mathbf{F e}_{3} \mathbf{O}_{\mathbf{4}}: \mathbf{P M M A} \\
{[\mathbf{w t} \%]}\end{array}$ & $\begin{array}{c}\mathbf{F e}_{\mathbf{3}} \mathbf{O}_{\mathbf{4}} \\
\mathbf{[ g ]}\end{array}$ & $\begin{array}{c}\mathbf{D N F} \\
{[\mathbf{g}]}\end{array}$ & $\begin{array}{c}\mathbf{C H C l}_{\mathbf{3}} \\
{[\mathbf{g}]}\end{array}$ & $\begin{array}{c}\text { PMMA } \\
{[\mathbf{g}]}\end{array}$ \\
\hline $\mathrm{S}_{\mathrm{a} 1}$ & $1: 1$ & 0.5000 & 0.7000 & 8.5000 & 0.5000 \\
\hline $\mathrm{S}_{\mathrm{a} 2}$ & $2: 1$ & 1.0000 & 0.7000 & 8.5000 & 0.5000 \\
\hline $\mathrm{S}_{\mathrm{a} 3}$ & $3: 1$ & 1.5000 & 0.7000 & 8.5000 & 0.5000 \\
\hline
\end{tabular}

Table 2. Compositions of the spinning dope II.

\begin{tabular}{|c|c|c|c|c|c|c|c|}
\hline $\begin{array}{c}\text { Spinning } \\
\text { dope II }\end{array}$ & $\begin{array}{c}\text { ANI/PMMA } \\
{[w t \%]}\end{array}$ & $\begin{array}{c}\text { ANI } \\
{[g]}\end{array}$ & $\begin{array}{c}\text { CSA } \\
{[\mathrm{g}]}\end{array}$ & $\begin{array}{c}\text { APS } \\
{[\mathrm{g}]}\end{array}$ & $\begin{array}{c}\text { DMF } \\
{[g]}\end{array}$ & $\begin{array}{c}\mathrm{CHCl}_{3} \\
{[\mathrm{~g}]}\end{array}$ & $\begin{array}{c}\text { PMMA } \\
{[\mathrm{g}]}\end{array}$ \\
\hline $\mathrm{S}_{\mathrm{b} 1}$ & 15 & 0.0900 & 0.1122 & 0.2204 & 2.0000 & 8.5000 & 0.6000 \\
\hline $\mathrm{S}_{\mathrm{b} 2}$ & 30 & 0.1800 & 0.2245 & 0.4471 & 2.0000 & 8.5000 & 0.6000 \\
\hline $\mathrm{S}_{\mathrm{b} 3}$ & 50 & 0.3000 & 0.3742 & 0.7351 & 2.0000 & 8.5000 & 0.6000 \\
\hline $\mathrm{S}_{\mathrm{b} 4}$ & 70 & 0.4200 & 0.5238 & 1.0200 & 2.0000 & 8.5000 & 0.6000 \\
\hline
\end{tabular}


ratio of $\mathrm{Tb}(\mathrm{BA})_{3}$ phen in PMMA was also $15 \%$. In a typical procedure, $0.075 \mathrm{~g} \mathrm{Eu}(\mathrm{BA})_{3}$ phen and $0.5 \mathrm{~g}$ PMMA were dissolved in a mixed solvent of $0.8 \mathrm{~g}$ DMF and $7.2 \mathrm{~g} \mathrm{CHCl}_{3}$ under magnetic stirring for $12 \mathrm{~h}$, and this mixture was used as spinning dopes III $\left(\mathrm{S}_{\mathrm{c}}\right)$. As for preparing $\mathrm{Tb}(\mathrm{BA})_{3}$ phen/PMMA nanofibers, $0.15 \mathrm{~g} \mathrm{~Tb}(\mathrm{BA})_{3}$ phen and $1 \mathrm{~g}$ PMMA were dispersed into a mixture of $1.0 \mathrm{~g}$ DMF and $9.0 \mathrm{~g} \mathrm{CHCl}_{3}$ under magnetic stirring for $12 \mathrm{~h}$, and this dope was applied as spinning dopes IV $\left(\mathrm{S}_{\mathrm{d}}\right)$.

\subsection{Fabrication of 2D BJP}

The electrospinning process of preparing 2D BJP was divided into three stages. The electrospinning conditions of the three stages were as follows. The distance between the spinneret and collector was 15 $\mathrm{cm}$ and a direct-current voltage of $7 \mathrm{kV}$ was used. The injection speed was $0.5 \mathrm{ml} \cdot \mathrm{h}^{-1}$ and the rotational speed of the roller was $1200 \mathrm{r} \cdot \mathrm{min}^{-1}$. The spinning process was carried out at a relative air humidity of $20-25 \%$ and an ambient temperature of $18-25^{\circ} \mathrm{C}$. The first stage was to obtain the $\left[\mathrm{Eu}(\mathrm{BA})_{3} \mathrm{phen} /\right.$ PMMA]//PANI/PMMA] Janus nanoribbons to form L-LRJF by using the biaxial electrospinning. First of all, $3 \mathrm{ml}$ of spinning dope II and $3 \mathrm{ml}$ of spinning dope III were respectively loaded into two parallel syringes connected with a home-made stainless steel parallel spinneret which was connected to a highvoltage supply, the rotating roller was used as a collector. When the spinning dopes were totally expended, the L-LRJF was obtained, and then the film was cut into a size of $2.2 \mathrm{~cm}$ in length and $2 \mathrm{~cm}$ in width. In order to carry out the second stage, the L-LRJF was rotated for $90^{\circ}$ and placed on the rotating roller with a piece of tin foil covering and $0.2 \mathrm{~cm}$ in length direction was not covered. The second biaxial electrospinning was performed under the same conditions using $3 \mathrm{ml}$ of spinning dope I and $3 \mathrm{ml}$ of spinning dope II. It was noted that the second biaxial electrospinning must rely on the side of the aboveprepared film that was not covered. After all the spinning dopes were totally used up, the product was removed from the rotating roller and the newly fabricated side denoted as R-LRJF was tailored to $2 \times 2 \mathrm{~cm}^{2}$. At this point, the LRJF as the top layer of the BJP with the area of $2 \times 4 \mathrm{~cm}^{2}$ was successfully prepared. The third stage was performed to obtain the down layer of the BJP. The traditional singleaxial electrospinning was employed in this stage. The LRJF was placed on the iron net which was used as the receiving device, and the $10 \mathrm{ml}$ of spinning dope IV was put in a single syringe. After the electrospinning process was finished, the NLF was successfully fabricated and trimmed to the same size as LRJF, as thus, the BJP was obtained.

For comparison, $\left\{\left[\mathrm{Eu}(\mathrm{BA})_{3}\right.\right.$ phen/PMMA $] / /(\mathrm{PANI} /$ $\mathrm{PMMA})\} \perp\left\{\left[\mathrm{Fe}_{3} \mathrm{O}_{4} / \mathrm{PMMA}\right] / /[\mathrm{PANI} / \mathrm{PMMA}]\right\}$ Janus nanoribbons non-array film and $\left[\mathrm{Tb}(\mathrm{BA})_{3}\right.$ phen/ PMMA] nanofibers non-array film (called as JNNFBJP), $\left[\mathrm{Eu}(\mathrm{BA})_{3}\right.$ phen/PANI/PMMA $] \perp\left[\mathrm{Fe}_{3} \mathrm{O}_{4} / \mathrm{PANI} /\right.$ PMMA] composite nanoribbons array film and [Tb(BA) $)_{3}$ phen/PMMA] nanofibers non-array film (defined as CNAF-BJP) and [Eu(BA) $)_{3}$ phen/PANI/ $\mathrm{PMMA}] \perp\left[\mathrm{Fe}_{3} \mathrm{O}_{4} / \mathrm{PANI} / \mathrm{PMMA}\right]$ composite nanoribbons non-array film and $\left[\mathrm{Tb}(\mathrm{BA})_{3}\right.$ phen/PMMA] nanofibers non-array film (denoted as CNNF-BJP) were prepared. The JNNF-BJP was fabricated under the same conditions as those for preparing BJP. First of all, spinning dope II $\left(\mathrm{S}_{\mathrm{b} 2}\right)$ and III, the spinning dope I ( $\left.\mathrm{S}_{\mathrm{a} 2}\right)$ and II $\left(\mathrm{S}_{\mathrm{b} 2}\right)$ were respectively electrospun into disordered Janus nanoribbons mat by using biaxial electrospinning as the left side and right side of the JNNF via employing an iron net as the collector, and thus non-array film was obtained. The nonarray film was cut into $2 \times 2 \mathrm{~cm}^{2}$ and placed on the iron net to form the JNNF. In the end, the spinning dope IV was electrospun to get the NLF on the JNNF as the down layer of the JNNF-BJP. To prepare CNAF-BJP and CNNF-BJP, mixed dope of spinning dope III and II $\left(\mathrm{S}_{\mathrm{b} 2}\right)$ was used to prepare composite nanoribbons to form the left sides of the CNAF and CNNF, and spinning dope I $\left(\mathrm{S}_{\mathrm{a} 2}\right)$ and II $\left(\mathrm{S}_{\mathrm{b} 2}\right)$ were also blended as the spinning dope to prepare composite nanoribbons to form the right sides of the CNAF and CNNF. In the above processes, the new spinning dopes were electrospun into composite nanoribbons array film (CNAF) and composite nanoribbons nonarray film (CNNF) by traditional single-axial electrospinning. The steps of preparing CNAF-BJP and CNNF-BJP were the same as those for the fabrication of JNNF-BJP.

\subsection{Characterization techniques}

A Hall effect measurement system (ECOPIA HMS3000) was applied to measure the electrical properties of the products. The Hitachi fluorescent spectrophotometer F-7000 (the excitation and emission slits were respectively 1.0 and $2.5 \mathrm{~nm}$ ) was utilized to investigate luminescent properties of the specimens. A scanning electron microscope (SEM, JSM-7610F) 
and an optical microscope (OM, CVM500E) were utilized to observe the morphology and internal structure of the products. The energy dispersive spectrometer (EDS, produced by Oxford Instruments) was used for elemental analyses. The phase compositions of as-prepared $\mathrm{Fe}_{3} \mathrm{O}_{4} \mathrm{NPs}$ and R-LRJP were analyzed via X-ray diffractometer (XRD, made by Bruker Corporation with the model of D8 FOCUS, and $\mathrm{Cu}$ $\mathrm{K} \alpha$ radiation, an acceleration voltage of $40 \mathrm{kV}$ and current of $20 \mathrm{~mA}$ were applied) to examine the phase compositions. A vibrating specimen magnetometer (VSM, purchased from Qunatum Design Inc. with the type of MPMS SQUID XL) was applied to determine supermagnetism.

\section{Results}

\subsection{Observation of morphology and internal structure of specimens}

Figure 2a shows the cross-section of the BJP, and the thickness of the NLF (down layer) and LRJF (top layer) are severally $c a .85 \mu \mathrm{m}$ and $c a .443 \mu \mathrm{m}$. Obvious delamination exists between LRJF and the NLF. On the top layer (LRJF), it is easy to find two groups of Janus nanoribbons array films, which are perpendicular to each other, LRJF and NLF are bound together to form BJP. Further shown in Figure 2b, two kinds of Janus nanoribbons are directionally aligned to form LRJF, in which the directions along

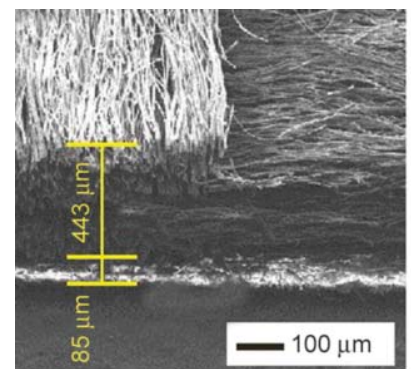

a)

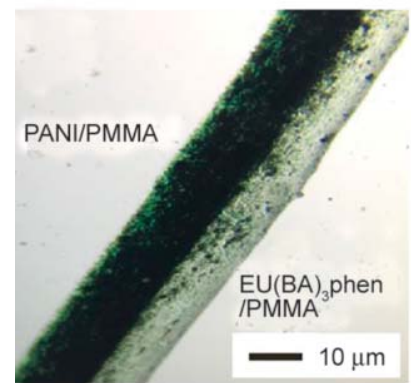

e)

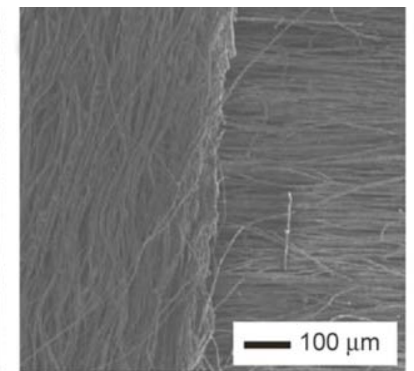

b)

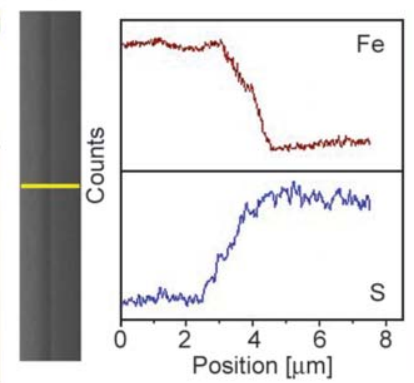

f)

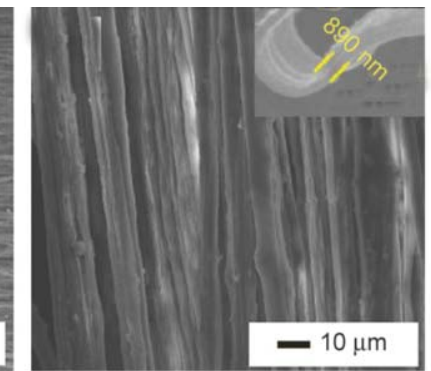

c)

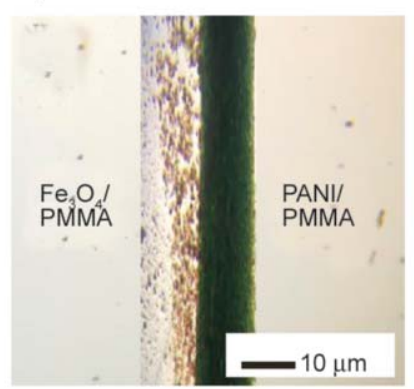

g) with the length direction of Janus nanoribbons, namely electrically conductive directions, are mutually vertical. Likewise, the directions along with the width directions of the Janus nanoribbons, namely electrically insulative directions, are also mutually perpendicular to produce double aeolotropic conduction. Figure 2c displays the high magnification SEM image of the Janus nanoribbons. The thickness and the width of the Janus nanoribbon are respectively $c a .890 \mathrm{~nm}$ and $8.7 \pm 0.3 \mu \mathrm{m}$. Figure $2 \mathrm{~d}-2 \mathrm{~g}$ display the EDS linescan analysis and $\mathrm{OM}$ images of the $\left[\mathrm{Eu}(\mathrm{BA})_{3}\right.$ phen/ PMMA]//PANI/PMMA] Janus nanoribbon and $\left[\mathrm{Fe}_{3} \mathrm{O}_{4} / \mathrm{PMMA}\right] / /[\mathrm{PANI} / \mathrm{PMMA}]$ Janus nanoribbon. EDS line analysis is used to examine the distribution of elements in the Janus nanoribbon. The $\mathrm{S}$ element represents the distribution of dark-green conductive material PANI, the Eu element is used to demonstrate the distribution of luminescent substance $\mathrm{Eu}(\mathrm{BA})_{3}$ phen and the $\mathrm{Fe}$ is utilized to indicate the distribution of magnetic substance $\mathrm{Fe}_{3} \mathrm{O}_{4}$. Figure $2 \mathrm{~d}$ illustrates the result of line analysis of $\left[\mathrm{Eu}(\mathrm{BA})_{3}\right.$ phen/ PMMA]//[PANI/PMMA] Janus nanoribbon. For Eu element, it is on the left part of the Janus nanoribbon, the S element is opposite to Eu element and only on the right part of the Janus nanoribbon. Figure $2 \mathrm{f}$ gives the result of line analysis of $\left[\mathrm{Fe}_{3} \mathrm{O}_{4} / \mathrm{PMMA}\right] / /$ [PANI/PMMA] Janus nanoribbon. The Fe element is distributed on the left part of the Janus nanoribbon

Figure 2. (a, b) SEM images of cross-section (a) and surface local morphology b) of BJP; (c) high magnification SEM image of Janus nanoribbons; (d, f) EDS line-scan analysis and (e, g) OM images of [Eu(BA) ${ }_{3}$ phen/PMMA]//PANI/ PMMA] Janus nanoribbon (d, e) and $\left[\mathrm{Fe}_{3} \mathrm{O}_{4} / \mathrm{PMMA}\right] / /[\mathrm{PANI} / \mathrm{PMMA}]$ Janus nanoribbon (f, g); (h) SEM image of NLF. 


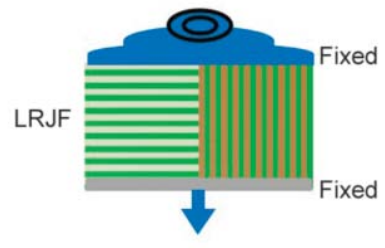

Load weight: $24.410 . \mathrm{g}$

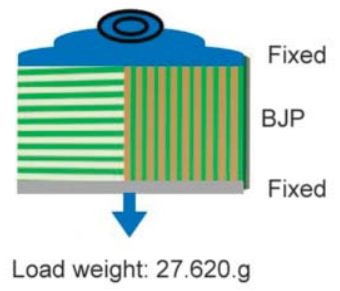

a)

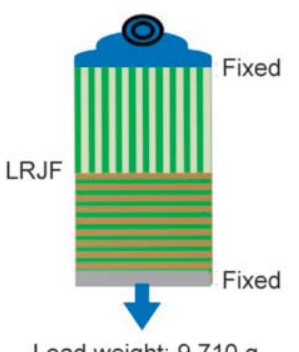

b)

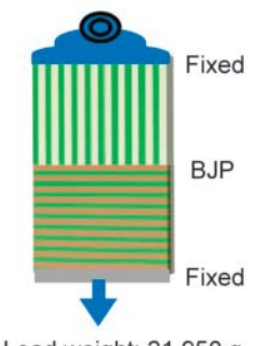

Load weight: $21.950 . \mathrm{g}$

Figure 3. Schematic diagram: breaking strength test of the (a) left-to-right direction and (b) up-to-down direction for the LRJF and BJP.

and the $\mathrm{S}$ element is distributed on the right part of the Janus nanoribbon. Figure 2e is OM image of $\left[\mathrm{Eu}(\mathrm{BA})_{3}\right.$ phen/PMMA]//[PANI/PMMA] Janus nanoribbon. The PANI is distributed on the black part and $\mathrm{Eu}(\mathrm{BA})_{3}$ phen on the white part. Figure $2 \mathrm{~g}$ is $\mathrm{OM}$ image of $\left[\mathrm{Fe}_{3} \mathrm{O}_{4} / \mathrm{PMMA}\right] / /$ PANI/PMMA] Janus nanoribbon with PANI distributed on one part of black and $\mathrm{Fe}_{3} \mathrm{O}_{4}$ on another part of light color. It is evident that the conductive material, magnetic material, and the luminescent material are respectively distributed on both parts of the Janus nanoribbon, and Janus nanoribbon is successfully prepared based on EDS line analysis and OM images. Figure $2 \mathrm{~h}$ illustrates the NLF in which the $\left[\mathrm{Tb}(\mathrm{BA})_{3}\right.$ phen/ PMMA] nanofibers are disordered and the diameter of the luminescent nanofibers is $c a .330 \pm 20 \mathrm{~nm}$. SEM analysis shows that the nanoribbons in the JNNF and CNNF are disordered, but the nanoribbons in the CNAF are orderly arranged in the same direction, and the width of the composite nanoribbons is $c a$. $5.7 \pm 0.1 \mu \mathrm{m}$.

Breaking strength tests for the top layer (LRJF) and whole pellicle (BJP) are performed to investigate the

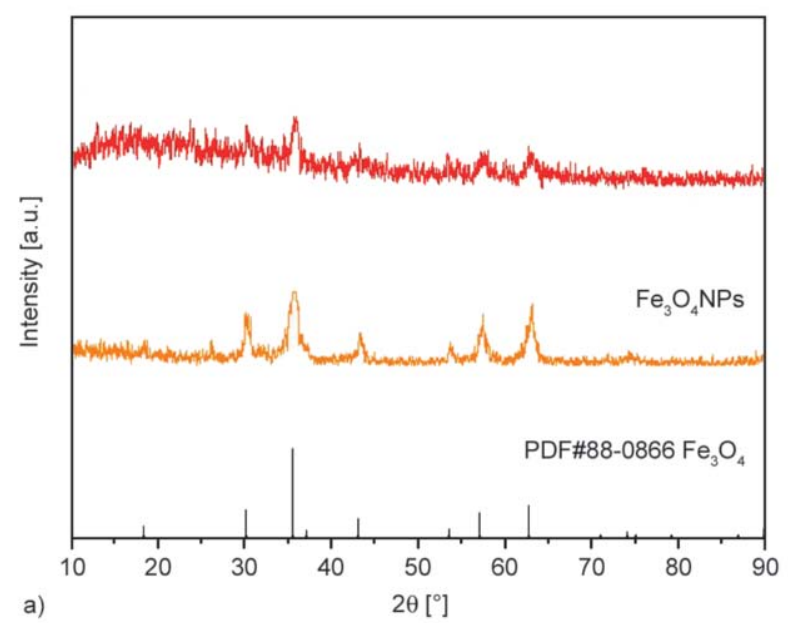

interfacial stability. The pellicles are respectively fixed in different directions, as shown in Figure 3. The interface is stable when the load weight is less than $24.410 \mathrm{~g}$ (Figure 3a) and $9.710 \mathrm{~g}$ (Figure 3b) for the LRJF, and $27.620 \mathrm{~g}$ (Figure 3a) and $21.950 \mathrm{~g}$ (Figure 3b) for the BJP, respectively. The data show that BJP has bigger breaking strength than LRJF in the two vertical directions and the existence of the down layer (NLF) can increase the strength of the entire pellicle.

\subsection{XRD and magnetic analysis}

Figure 4a demonstrates XRD analytical results of the as-prepared $\mathrm{Fe}_{3} \mathrm{O}_{4}$ NPs and R-LRJF. The XRD patterns of the as-prepared $\mathrm{Fe}_{3} \mathrm{O}_{4} \mathrm{NPs}$ are conformed to the cubic structure of $\mathrm{Fe}_{3} \mathrm{O}_{4}(\mathrm{PDF} \# 88-0866)$, and there are no characteristic peaks corresponding to other impure compounds. As for the R-LRJF, diffraction peaks of $\mathrm{Fe}_{3} \mathrm{O}_{4}$ can be detected, implying that $\mathrm{Fe}_{3} \mathrm{O}_{4}$ NPs are decentralized in the R-LRJF. Figure $4 \mathrm{~b}$ displays the hysteresis loops of R-LRJF with different ratios of $\mathrm{Fe}_{3} \mathrm{O}_{4}$ to PMMA when the percentage of PMMA to PANI is $30 \%$. It is a well-known fact that

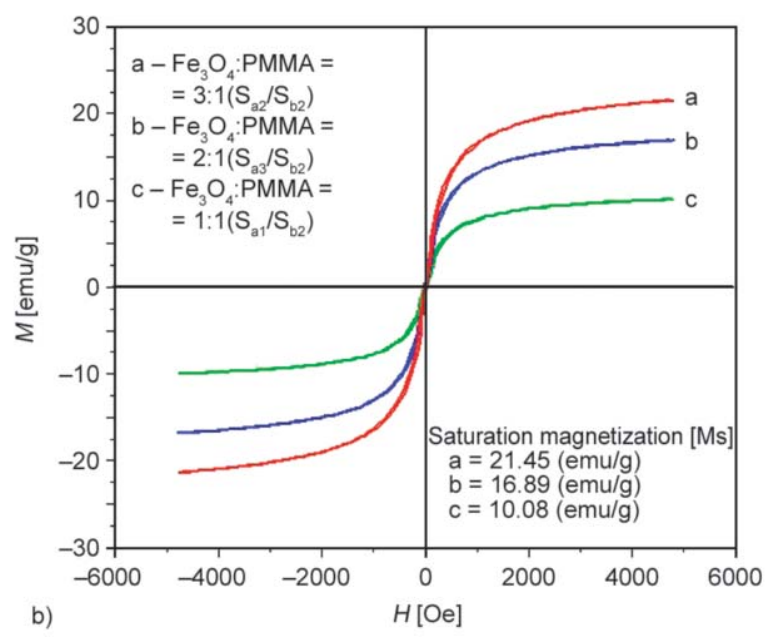

Figure 4. (a) XRD results of the as-prepared $\mathrm{Fe}_{3} \mathrm{O}_{4}$ NPs and R-LRJF; (b) hysteresis loops of R-LRJF with different ratios of $\mathrm{Fe}_{3} \mathrm{O}_{4}$ to PMMA. 
the saturation magnetizations of magnetic composite materials rely on the mass ratio of the magnetic substance in the composites. When the ratios of $\mathrm{Fe}_{3} \mathrm{O}_{4}$ to PMMA change from 1:1 to $3: 1$, the saturation magnetization augments from $10.08(\mathrm{emu} / \mathrm{g})$ to $21.45(\mathrm{emu} / \mathrm{g})$ with more $\mathrm{Fe}_{3} \mathrm{O}_{4} \mathrm{NPs}$ introduced. The change in saturation magnetization clearly indicates that the superparamagnetic properties of R-LRJF are adjustable.

\subsection{Luminescent performance}

The luminescent properties of the L-LRJF and NLF are investigated. The excitation spectra of L-LRJF is obtained by monitoring wavelength at $615 \mathrm{~nm}$ and exhibit the strongest excitation peaks at $291 \mathrm{~nm}$, which are assigned to $\pi \rightarrow \pi^{*}$ electron transition of ligands. The $\mathrm{Eu}^{3+}$ ion is a well-known red emitting material due to the red emissions from ${ }^{5} \mathrm{D}_{0} \rightarrow{ }^{7} \mathrm{~F}_{\mathrm{J}}$ transitions $(J=0,1,2,3$ and 4). Using $291 \mathrm{~nm}$ as the excitation wavelength, the emission spectra of the L-LRJF are obtained, as shown in Figure 5a. It exhibits the strongest emission band at $615 \mathrm{~nm}$ and several other peaks which are situated at 581, 592, 615 , and $620 \mathrm{~nm}$, respectively. These peaks are respectively attributed to ${ }^{5} \mathrm{D}_{0} \rightarrow{ }^{7} \mathrm{~F}_{0}(581 \mathrm{~nm}),{ }^{5} \mathrm{D}_{0} \rightarrow{ }^{7} \mathrm{~F}_{1}$ $(592 \mathrm{~nm}),{ }^{5} \mathrm{D}_{0} \rightarrow{ }^{7} \mathrm{~F}_{2}(615,620 \mathrm{~nm})$ energy level transitions of $\mathrm{Eu}^{3+}$. As shown in Figure 5a, the spectral shape of L-LRJF remain unchanged with the augment of PANI content, but the excitation and emission spectra intensity gradually reduce, and the emission intensity is the strongest when the mass ratio of PANI to PMMA is $15 \%$ in this study. Since the PANI absorbs ultraviolet light and visible light [50], the addition of PANI weakens the excitation light and the light emitted by the L-LRJF. Therefore, when the intensity of the excitation light keeps the same, the higher the content of PANI in the Janus nanoribbons, the greater the more reduced the intensity of the emitted light. For L-LRJF, it is further found that no characteristic emitting peaks of $\mathrm{Tb}^{3+}$ are detected, implying that the NLF has no effect on the luminescence of the LRJF.

Figure $5 b, 5 c$ reveal the emission spectra of NLF with different PANI percentages of the L-LRJF (Figure 5b) and various PANI and $\mathrm{Fe}_{3} \mathrm{O}_{4}$ contents of the R-LRJF (Figure 5c), respectively, and the strongest excitation peak is obtained at $294 \mathrm{~nm}$. The emission peaks are attributed to ${ }^{5} \mathrm{D}_{4} \rightarrow{ }^{7} \mathrm{~F}_{\mathrm{J}}(J=6,5,4$ and 3$)$ transitions of $\mathrm{Tb}^{3+}$ at $489 \mathrm{~nm}\left({ }^{5} \mathrm{D}_{4} \rightarrow{ }^{7} \mathrm{~F}_{6}\right), 545 \mathrm{~nm}$ $\left({ }^{5} \mathrm{D}_{4} \rightarrow{ }^{7} \mathrm{~F}_{5}\right), \quad 586 \mathrm{~nm} \quad\left({ }^{5} \mathrm{D}_{4} \rightarrow{ }^{7} \mathrm{~F}_{4}\right)$, and $620 \mathrm{~nm}$
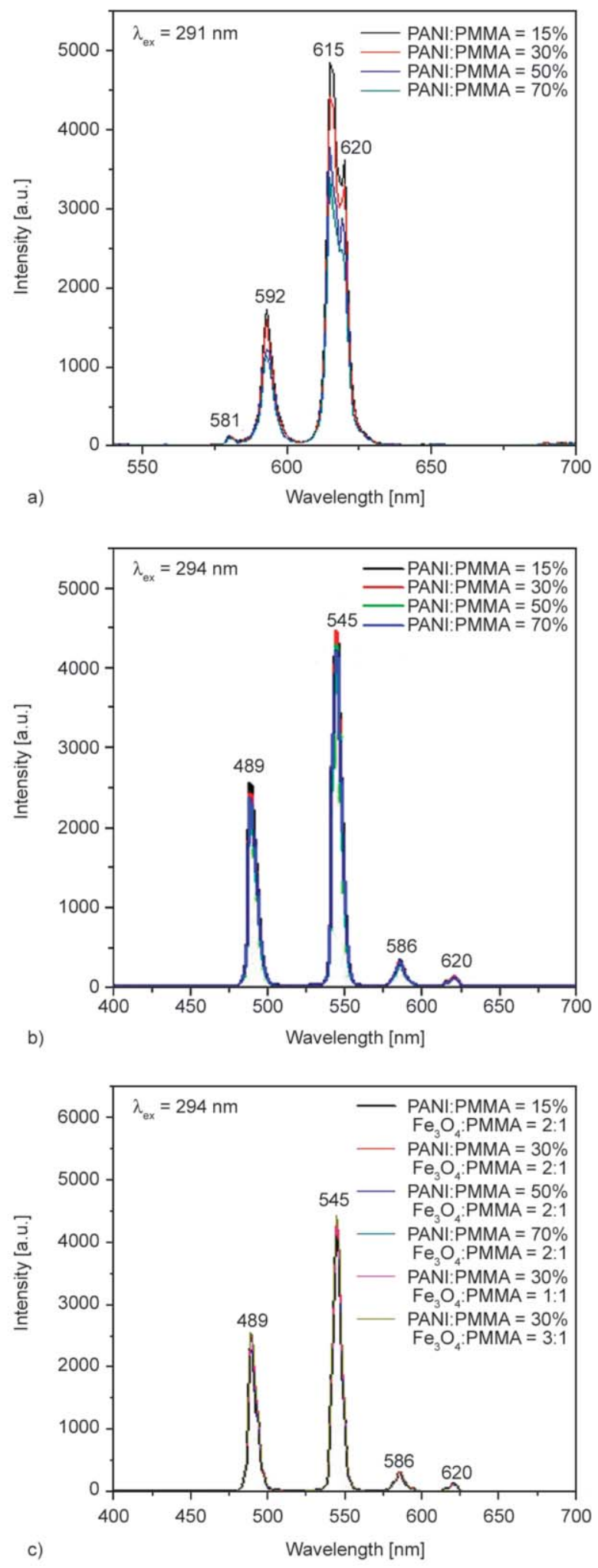

Figure 5. Emission spectra of (a) L-LRJF with various PANI percentages; (b, c) NLF with different PANI percentages of the L-LRJF (b) and various PANI and $\mathrm{Fe}_{3} \mathrm{O}_{4}$ contents of the R-LRJF (c).

$\left({ }^{5} \mathrm{D}_{4} \rightarrow{ }^{7} \mathrm{~F}_{3}\right)$. The $\mathrm{Tb}(\mathrm{BA})_{3}$ phen/PMMA nanofibers exhibit the strongest emission band at $545 \mathrm{~nm}$. It can be seen that the emission spectrum intensity of NLF is 


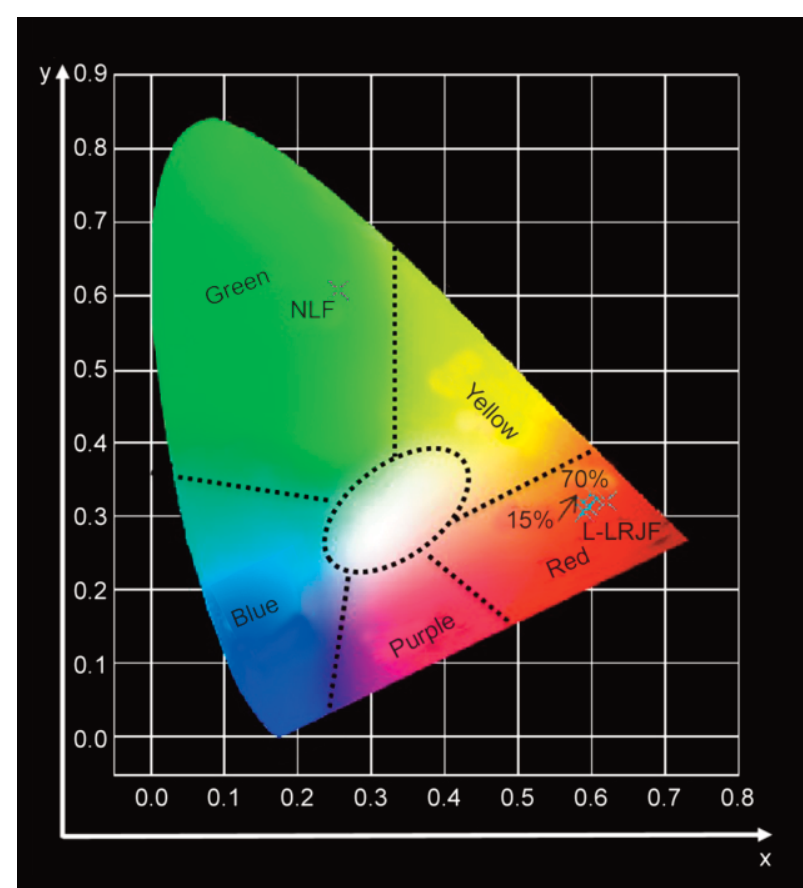

Figure 6. CIE chromaticity coordinates diagram of L-LRJF and NLF.

substantially unchanged with the increase in $\mathrm{Fe}_{3} \mathrm{O}_{4}$ NPs and PANI content, and no characteristic emission peaks of $\mathrm{Eu}^{3+}$ are detected. The intensity of the emission peaks does not change owing to the fact that the LRJF and NLF form two independent regions without any mutual influences, indicating that the structure of BJP possesses great preponderances in constructing advanced materials of multi-functionality, and the LRJF has no effect on the luminescence of the NLF. Figure 6 is the CIE coordinates chromaticity diagram of L-LRJF and NLF under the excitation of 291 and $294 \mathrm{~nm}$ ultraviolet light, respectively, which shows that the colors of the two layers are respectively red and green in darkness. The colors of physical-digital photos of samples under the daylight are respectively dark green and white.

Luminescence performances of the JNNF-BJP, CNAF-BJP, and CNNF-BJP are also comparatively studied. The emission spectra of the left sides of the top layer of specimens are demonstrated in Figure 7a. It can be seen from the figures that the spectral intensity of the JNNF-BJP is slightly reduced compared to that of the BJP, but the spectral intensity of the CNAF-BJP and CNNF-BJP is greatly reduced. The arrangement of nanoribbons in BJP is very tight. When the excitation light is irradiated to the surface of the specimen, it is difficult for the excitation light to reach the bottom layer of the Janus nanoribbons through the top layer and the intensity of emitted light
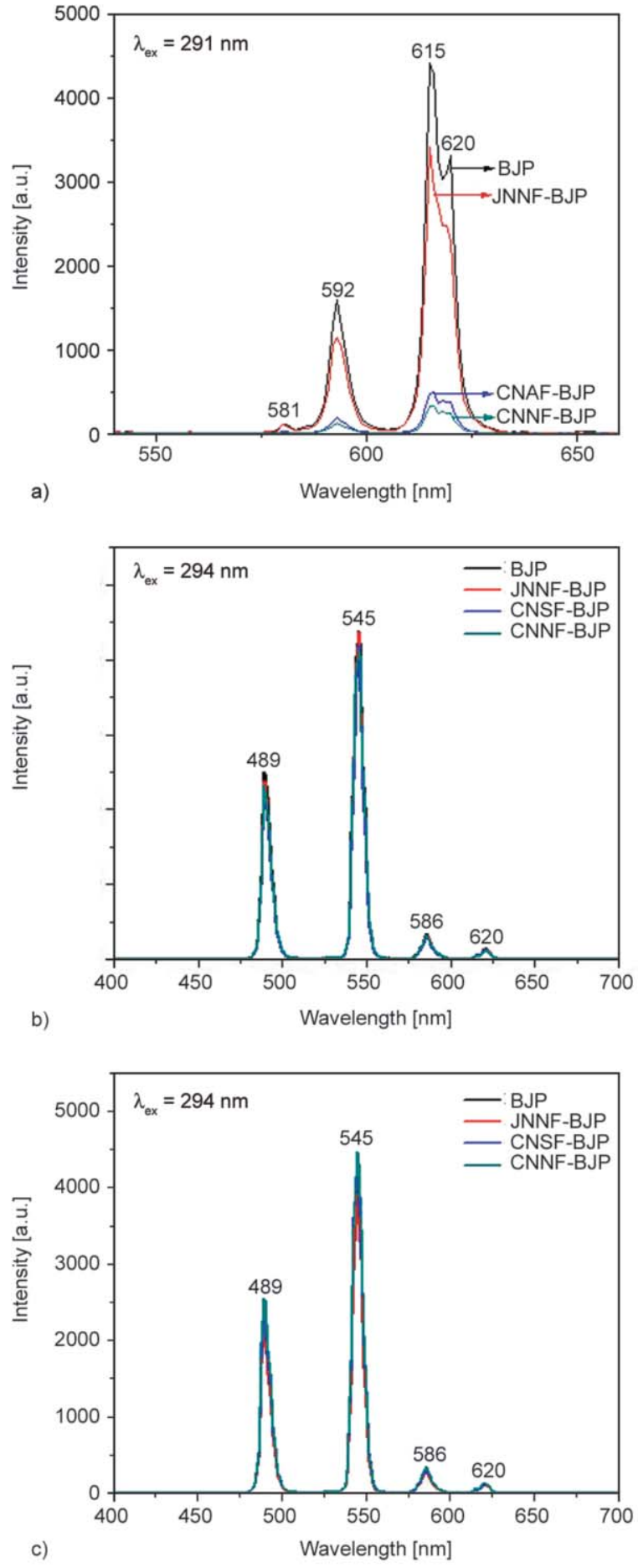

Figure 7. Emission spectra of left side of up layer (a), and left side (b) and right side (c) of down layer (b, c) of BJP, JNNF-BJP, CNAF-BJP and CNNF-BJP.

is not weakened. However, the Janus nanoribbons in the JNNF-BJP are disordered. When the excitation light is irradiated on the specimen surface, part of the excitation light passes through the top layer to the bottom layer of the Janus nanoribbons and is absorbed, and the intensity of emission light is weakened. Due to the separation of the light-emitting region from the 
conductive region in the Janus nanoribbon, JNNFBJP still maintains excellent luminescent intensity. The composite nanoribbons in CNAF-BJP are prepared by using the single-axial electrospinning, and thus the light-emitting part and the conductive part are not separated. It can be seen that the decrease of luminescent intensity of CNAF-BJP is caused by the incorporation of PANI, the more PANI contains, the weaker the luminescent intensity of CNAF-BJP becomes. The luminescent intensity of the CNAF-BJP is slightly bigger than that of CNNF-BJP due to the same reason as that for BJP and JNNF-BJP. Therefore, the BJP has stronger luminescent intensity than the three comparative specimens, fully implying that BJP has more structural superiority. We also determine the emission spectra of the down layer of the JNNF-BJP, CNAF-BJP, and CNNF-BJP. It can be seen from Figure $7 \mathrm{~b}, 7 \mathrm{c}$ that the luminescent property of the down layer is not affected by the change of the top layer. It can be concluded that two layers in the specimens are reciprocally independent, and the excitation light is hard to pass through the down layer to the top layer of the pellicle, leading to the result that the down layer is not affected by the top layer.

\subsection{Electrically conductive properties}

A series of specimens were tested in order to research the conductivity of BJP, JNNF-BJP, CNAFBJP and CNNF-BJP. For the four specimens, all of NLF (down layer) in specimens are insulative in electrical conduction. The electrical properties of the top layers of the four specimens are studied. For the testing specimens, the mass percentages of PANI to PMMA are varied from 15, 30, 50 and $70 \%$ and the mass ratios of $\mathrm{Fe}_{3} \mathrm{O}_{4}$ to PMMA are varied from 1:1, $2: 1$ and $3: 1$. The LRJF consists of $\left[\mathrm{Eu}(\mathrm{BA})_{3} \mathrm{phen} /\right.$ PMMA]//[PANI/PMMA] Janus nanoribbons at the left side and $\left(\mathrm{Fe}_{3} \mathrm{O}_{4} / \mathrm{PMMA}\right) /(\mathrm{PANI} / \mathrm{PMMA})$ Janus nanoribbons at the right side. The Janus nanoribbon is composed of two parts, including conductive PANI with PMMA part and insulated $\mathrm{Eu}(\mathrm{BA})_{3}$ phen/ PMMA or $\mathrm{Fe}_{3} \mathrm{O}_{4}$ with PMMA part. The LRJF is electrically conductive in the direction of the PANI arrangement because the distribution of PANI in the nanoribbons owns ideal directional continuity which provides for electron transport pathway. The LRJF is insulative in the direction perpendicular to the alignment of the PANI because non-conductive elements are inserted into this direction, which prevents the transport of electrons. Figure 8 displays
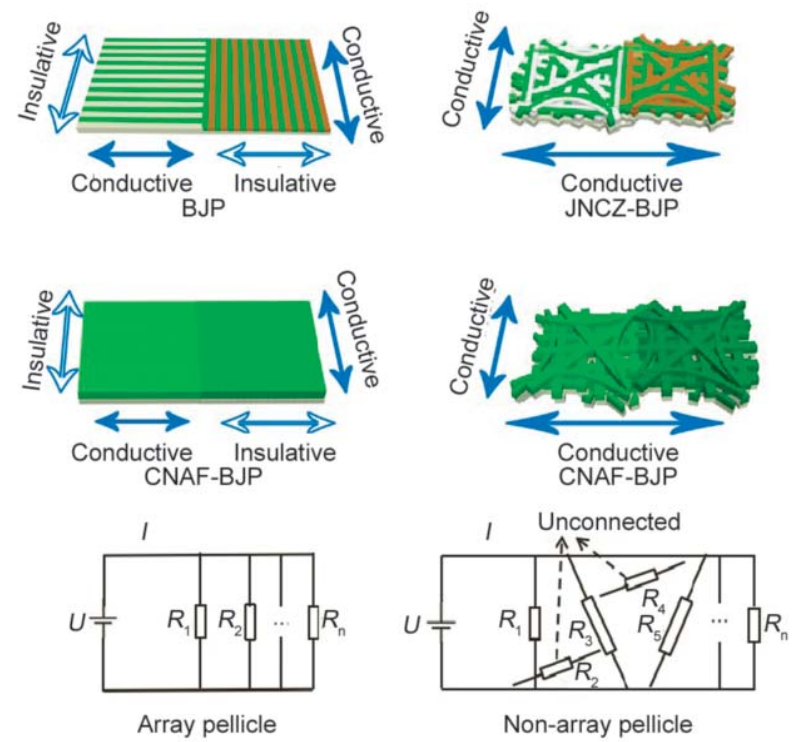

Figure 8. Schematic of conductivity of BJP, JNNF-BJP, CNAF-BJP, CNNF-BJP and physical circuit illustrative diagrams corresponding to array film and non-array film.

the conductivity schematic of the LRJF of BJP, and it can be observed that the LRJF has two different ways of conducting. For the L-LRJF, it conducts along the length of the specimen and insulates along with the width of the specimen. For the R-LRJF, it conducts along the width of the specimen and insulates in the length direction of the specimen. L-LRJF and R-LRJF respectively possess aeolotropic conduction. Further, the conductive directions of the LRJF on the left side and right side are vertical and the entire specimen is insulated along with the length of the specimen, and thus the LRJF offers double conductive aeolotropism. The test method is based on reference [50]. During the process of testing conductivity, the conductance along the conductive direction of L-LRJF is expressed as $L_{\mathrm{c}}$, and the conductance along with the insulative direction is denoted as $L_{\mathrm{i}}$. The conductance along the conductive direction of the R-LRJF is named as $R_{\mathrm{c}}$, the conductance along with the insulative direction is defined as $R_{\mathrm{i}}$. The conductance along with the left-to-right direction of the entire specimen is indicated as $(L-$ $R)_{\mathrm{i}}$ and conductance test results are summarized in Table 3.

When the mass percentage of PANI to PMMA is changed from 15 to $70 \%$, the electrical conductance of conductive direction of the BJP increases from the order of $10^{-6}$ to $10^{-2} \mathrm{~S}$, and the electrical conductance in the insulating direction is still $10^{-10} \mathrm{~S}$, and furthermore, the increase in $\mathrm{Fe}_{3} \mathrm{O}_{4} \mathrm{NPs}$ content does 
Table 3. The conductance of the BJP with different mass percentages of PANI to PMMA and the three contrast specimens.

\begin{tabular}{|c|c|c|c|c|c|c|c|c|}
\hline \multirow[t]{2}{*}{ Specimens } & \multicolumn{7}{|c|}{$\begin{array}{c}\text { Conductance } \\
{[\mathrm{S}]}\end{array}$} & \multirow{2}{*}{$\begin{array}{c}\text { Aeolotropism } \\
\text { degree }\end{array}$} \\
\hline & $L_{\mathrm{c}}$ & $L_{\mathrm{i}}$ & $R_{\mathrm{c}}$ & $R_{\mathrm{i}}$ & $L_{\mathrm{c} / \mathrm{i}}$ & $R_{\mathrm{c} / \mathrm{i}}$ & $(L-R)_{\mathrm{i}}$ & \\
\hline $\begin{array}{l}\mathrm{BJP}(\mathrm{PANI}: \mathrm{PMMA}=15 \%, \\
\left.\mathrm{Fe}_{3} \mathrm{O}_{4}: \mathrm{PMMA}=2: 1\right)\end{array}$ & $2.19 \cdot 10^{-6}$ & $1.32 \cdot 10^{-10}$ & $2.16 \cdot 10^{-6}$ & $1.25 \cdot 10^{-10}$ & $1.66 \cdot 10^{4}$ & $1.73 \cdot 10^{4}$ & $4.65 \cdot 10^{-10}$ & Weak \\
\hline $\begin{array}{l}\text { BJP }(\text { PANI:PMMA }=30 \%, \\
\left.\mathrm{Fe}_{3} \mathrm{O}_{4}: \text { PMMA }=2: 1\right)\end{array}$ & $6.35 \cdot 10^{-5}$ & $1.55 \cdot 10^{-10}$ & $6.96 \cdot 10^{-5}$ & $1.76 \cdot 10^{-10}$ & $4.10 \cdot 10^{5}$ & $3.95 \cdot 10^{5}$ & $7.49 \cdot 10^{-10}$ & Medium \\
\hline $\begin{array}{l}\mathrm{BJP}(\mathrm{PANI}: \mathrm{PMMA}=50 \%, \\
\left.\mathrm{Fe}_{3} \mathrm{O}_{4}: \mathrm{PMMA}=2: 1\right)\end{array}$ & $1.52 \cdot 10^{-4}$ & $1.43 \cdot 10^{-10}$ & $1.48 \cdot 10^{-4}$ & $1.57 \cdot 10^{-10}$ & $1.06 \cdot 10^{6}$ & $0.94 \cdot 10^{6}$ & $2.74 \cdot 10^{-10}$ & Strong \\
\hline $\begin{array}{l}\text { BJP (PANI:PMMA=70\%, } \\
\left.\mathrm{Fe}_{3} \mathrm{O}_{4}: \mathrm{PMMA}=2: 1\right)\end{array}$ & $3.78 \cdot 10^{-2}$ & $1.89 \cdot 10^{-10}$ & $4.37 \cdot 10^{-2}$ & $1.78 \cdot 10^{-10}$ & $2.00 \cdot 10^{8}$ & $2.45 \cdot 10^{8}$ & $2.91 \cdot 10^{-10}$ & Very strong \\
\hline $\begin{array}{l}\text { BJP (PANI:PMMA }=30 \%, \\
\left.\mathrm{Fe}_{3} \mathrm{O}_{4}: \mathrm{PMMA}=1: 1\right)\end{array}$ & $6.33 \cdot 10^{-5}$ & $1.45 \cdot 10^{-10}$ & $6.76 \cdot 10^{-5}$ & $1.75 \cdot 10^{-10}$ & $4.36 \cdot 10^{5}$ & $3.86 \cdot 10^{5}$ & $7.25 \cdot 10^{-10}$ & Medium \\
\hline $\begin{array}{l}\mathrm{BJP}(\mathrm{PANI}: \mathrm{PMMA}=30 \%, \\
\left.\mathrm{Fe}_{3} \mathrm{O}_{4}: \mathrm{PMMA}=3: 1\right)\end{array}$ & $6.95 \cdot 10^{-5}$ & $1.59 \cdot 10^{-10}$ & $6.56 \cdot 10^{-5}$ & $1.72 \cdot 10^{-10}$ & $4.37 \cdot 10^{5}$ & $3.81 \cdot 10^{5}$ & $7.85 \cdot 10^{-10}$ & Medium \\
\hline JNNF-BJP & $1.16 \cdot 10^{-8}$ & $1.10 \cdot 10^{-8}$ & $1.25 \cdot 10^{-8}$ & $1.24 \cdot 10^{-8}$ & 1.05 & 1.00 & $7.89 \cdot 10^{-9}$ & None \\
\hline CNAF-BJP & $2.00 \cdot 10^{-9}$ & $2.14 \cdot 10^{-10}$ & $2.23 \cdot 10^{-9}$ & $2.45 \cdot 10^{-10}$ & 9.34 & 9.10 & $1.07 \cdot 10^{-10}$ & Very weak \\
\hline CNNF-BJP & $1.19 \cdot 10^{-9}$ & $1.16 \cdot 10^{-9}$ & $1.32 \cdot 10^{-9}$ & $1.55 \cdot 10^{-9}$ & 1.02 & 0.85 & $8.43 \cdot 10^{-9}$ & None \\
\hline
\end{tabular}

not affect the conductance of BJP. For the BJP, it can be seen that a higher conductance in the conductive direction can be obtained with the augment of PANI content, and the electrical conductance in the direction of insulation does not change. As a result, the ratio between electrical conductance in the conductive direction and electrical conductance in the insulating direction becomes larger, that is, the degree of aeolotropism becomes larger. Compared with the BJP, the JNNF-BJP has no aeolotropic conduction properties. Due to the random arrangement of the Janus nanoribbons, the JNNF-BJP is conductive in all directions and thus has no aeolotropic conductive properties.

In the test process, a certain voltage $(U)$ is exerted on both ends of the specimen and nanoribbons parallelly link in the circuit, which can be compared with the parallel circuit in physics. The characteristic of a parallel circuit is that each component is parallelly connected in the circuit and the magnitude of the current is as following: $I=I_{1}+I_{2}+\ldots+I_{\mathrm{n}}$, where $I$ is current, $n$ is the number of components in physics, here we refer to the number of nanoribbons. The magnitude of the electrical conductance $(C)$ is given by the following formula: $C=I / U$, when the voltage $(U)$ is constant, electrical conductance $(C)$ decreases as the current value (I) diminishes, and vice versa. As shown in Figure 8, a physical circuit diagram is used to simulate the connection of a specimen to a circuit for conductivity measurement, and the physical symbol ' $\square \square$ - 'represents the nanoribbons. The nanoribbons array film is built by the same length of nanoribbons orderly connected side by side along the array direction and each Janus nanoribbon has the same resistance and the current. For the non-array film, the length of the nanoribbons connected to the circuit becomes larger due to the disordered arrangement of the Janus nanoribbons, and thus, the resistance of the nanoribbons becomes larger and the current becomes smaller. Another reason is that some nanoribbons are not connected to the two measuring electrodes, resulting in a decrease in the number of nanoribbons connected to the circuit, leading to decrease in value of ' $n$ ' and the current becomes smaller. The above two reasons lead to a decrease in the current of the JNNF-BJP. Therefore, compared with BJP, JNNF-BJP has lower electrical conductance. CNNF-BJP and CNAF-BJP have lower conductance than the JNNF-BJP, this is because non-conductive substances rare earth complexes are introduced into the composite nanoribbons and hinder the formation of the PANI conductive network. For the CNAF-BJP, the interfaces among the composite nanoribbons are utilized as an insulating medium, but the aeolotropism is very weak because of insufficient insulation, and the CNNF-BJP has no conductive aeolotropism owing to the disordered arrangement of composite nanoribbons. The above results show that the BJP achieves excellent double aeolotropic conduction and a high degree of conductive aeolotropism.

The specimens are also used as the conductor in the simple circuits, in which a LED bulb (12 watts) as an indicator light and a transformer as a power source are included. It can be seen from Figure 9 that 


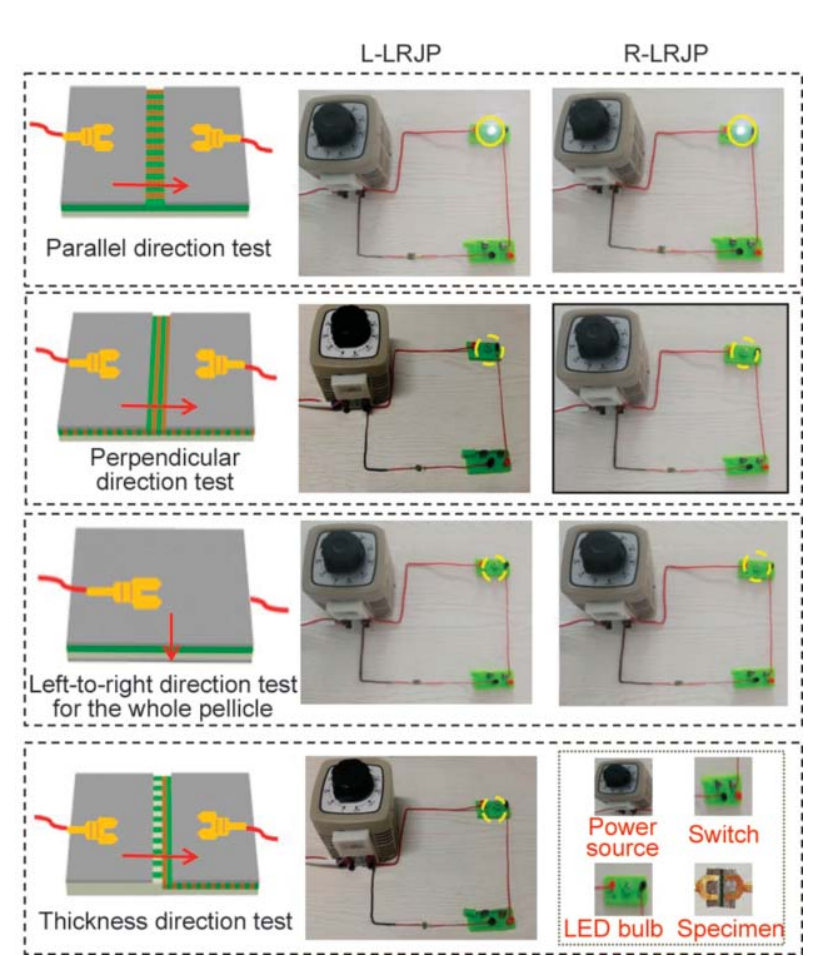

Figure 9. Digital photos of the electrical testing through the simple circuit (the red arrows indicate the direction of test).

the LED bulb can be lightened when the test direction is the direction parallel to the Janus nanoribbons, the LED bulb is off when the test directions are the direction perpendicular to the Janus nanoribbons, thickness direction and left-to-right direction for the whole pellicle. During the tests, L-LRJF and the R-LRJF have the same experimental phenomenon. When the voltage value is increased during the test, the bulb becomes brighter, but the operating voltage of the entire circuit cannot exceed $30 \mathrm{~V}$. These experimental phenomena more intuitively prove that BJP has excellent electrical conductivity and high aeolotropic conductivity, implying that BJP has many potential practical values in flexible devices.

\subsection{Designing, fabrication, and performance of 3D dual-wall Janus-type tube}

Four kinds of 3D dual-wall Janus-type tubes are designed and fabricated by rolling the 2D BJP. There are two preparative schemes, the first scheme is to obtain the dual-wall Janus-type tube a (marked as DW-a) and dual-wall Janus-type tube $b$ (defined as DW-b) with the left and right structure. The left and right edges of the BJP are synchronously rolled up or down respectively until the two edges are bound together to form the closed tube to obtain DW-a or

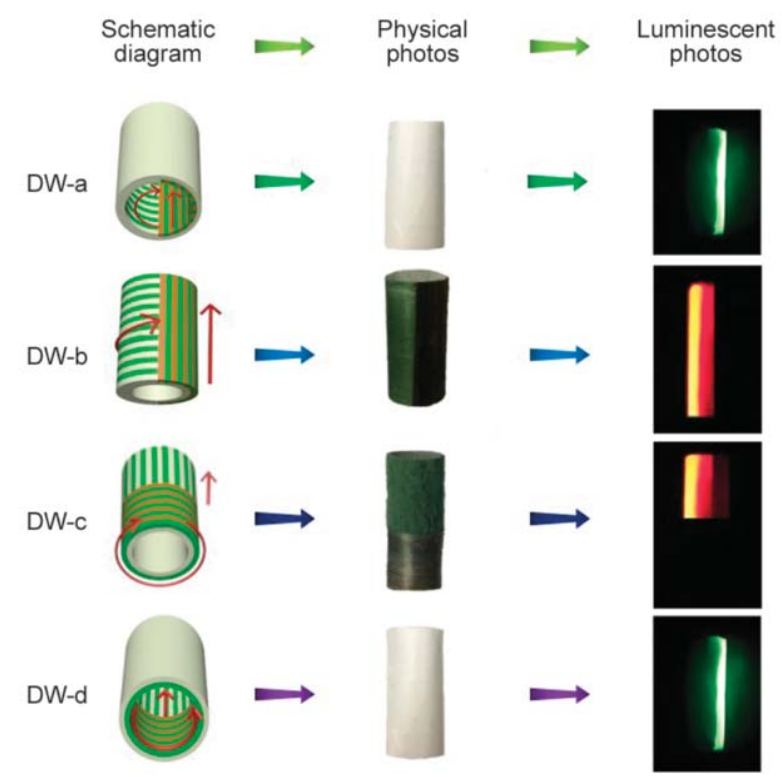

Figure 10. Schematic diagram, physical photos and luminescent photos under UV illumination of the $3 \mathrm{D}$ dual-wall Janus-type tube (the red arrows indicate the direction of conduction).

DW-b. The second scheme is to acquire the dualwall Janus-type tube c (denoted as DW-c) and dualwall Janus-type tube d (named as DW-d) with the top and down structure. The top and down edges of the BJP are simultaneously rolled down or up respectively until the two edges are contacted together to form the closed tube to acquire DW-c or DW-d. Furthermore, it is facile to obtain tubes with different performances and morphological characteristics such as aperture and thickness by adjusting the fabrication parameters.

It is very interesting to see that different structures of tubes can be gained by rolling of BJP from different directions. Figure 10 shows the schematic diagram, physical photos and luminescent photos under UV illumination of the 3D dual-wall Janus-type tube obtained by rolling the BJP. According to the different direction of electrical conduction, four kinds of dualwall Janus-type tube are successfully designed and fabricated. The inner wall of the DW-a and the outer wall of DW-b are Janus-type tubes which is left-right structure and divided into two halves along the perimeter. One half with red luminescence illuminated by UV light is conductive along the circumferential direction and insulated along the axial direction. The another half is conductive in the axial direction and insulated in the circumferential direction, and conductive directions of the two halves are mutually perpendicular. The outer wall of the DW-a and the inner wall of DW-b are insulative and homogeneous 
tube of green luminescence irradiated by UV light. Meanwhile, outer wall of the DW-c and inner wall of the DW-d are Janus-type tubes which are topdown structure and divided along the axis into two halves. One half conducts along the axis and insulated in the circumferential direction and emits red luminescence irradiated by UV light. The another half with superparamagnetism is insulated in the axial direction and conductive in the circumferential direction, and the conductive directions of the two halves are also reciprocally perpendicular. Both the inner wall of DW-c and outer wall of DW-d are the insulating and homogeneous tube of green luminescence excited by UV light. The dual-wall Janus-type tubes have the same electrical, luminescent and superparamagnetic properties as the 2D BJP. Consequently, the novel four kinds of flexible 3D Janustype tubes exhibit multifunctionaties of double conductive aeolotropism, dual-colored luminescence and superparamagnetism. This designing philosophy and fabrication scheme realize the transformation of multi-functional aeolotropic conductive materials from $2 \mathrm{D}$ to $3 \mathrm{D}$.

\section{Conclusions}

The new type of 2D flexible bilayer Janus pellicle (BJP) and 3D dual-wall Janus-type tubes endued with multi-functionality of double electrically conductive aeolotropism, superparamagnetism and luminescence are designed and prepared for the first time. The top layer of the BJP is a left-right structured Janus film composed of Janus nanoribbons and conducts electricity in the direction of the nanoribbons arrangement, resulting in double aeolotropic conductivity. The electrical conductance of BJP can reach $10^{-2} \mathrm{~S}$, and the conduction ratio reaches $10^{8}$ times between conductive and insulating direction of the BJP. The down layer is a non-array luminescent film composed of nanofibers. Red and green emission of L-LRJF and NLF are obtained under excitation at 291 and $294 \mathrm{~nm}$, respectively. The properties of the superparamagnetism of the R-LRJF can be adjusted by changing the content of $\mathrm{Fe}_{3} \mathrm{O}_{4} \mathrm{NPs}$. In addition, the luminescence and conducting properties between the two layers hardly affect each other. The four kinds of 3D dual-wall Janus-type tubes were obtained by rolling the 2D BJP, and the direction of conduction can be controlled by changing the rolling direction. We have successfully realized the transition from 1D nanofibers and Janus nanoribbons to 2D double aeolotropic conductive Janus pellicle then to 3D dualwall Janus-type tube and achieved high integration of three functions in a single material with adjustable characteristics. This special multifunctional 3D dualwall Janus-type tube and 2D flexible BJP may have potential applications in the fields of electromagnetic shielding, light emitting devices, sensors and flexible devices, and they also provide a new material basis for the development of nanotechnology and some related science and technology. The designing philosophy and construction technique offer to construct new typed Janus materials of multi-functionality.

\section{Acknowledgements}

This work was financially supported by National Natural Science Foundation of China (51573023, 51803012), Natural Science Foundation of Jilin Province (20170101101JC, 20180520011JH), Science and Technology Research Planning Project of the Education Department of Jilin Province during the $13^{\text {th }}$ five-year plan period (JJKH20170608KJ, JJKH20181122KJ), and Innovative Foundation (XJJLG-201704) and Youth Foundation (XQNJJ-2016-01, XQNJJ-201717) of Changchun University of Science and Technology.

\section{References}

[1] Yang H-C., Xie Y., Hou J., Cheetham A. K., Chen V., Darling S. B.: Janus membranes: Creating asymmetry for energy efficiency. Advanced Materials, 30, 1801495/1-1801495/11 (2018). https://doi.org/10.1002/adma.201801495

[2] Jiang Z., He J., Deshmukh S. A., Kanjanaboos P., Kamath G., Wang Y. F., Sankaranarayanan S. K. R. S., Wang J., Jaeger H. M., Lin X-M.: Subnanometre ligand-shell asymmetry leads to Janus-like nanoparticle membranes. Nature Materials, 14, 912-917 (2015). https://doi.org/10.1038/nmat4321

[3] Cobo S., Heidkamp J., Jacques P-A., Fize J., Fourmond V., Guetaz L., Jousselme B., Ivanova V., Dau H., Palacin S., Fontecave M., Arero V.: A Janus cobaltbased catalytic material for electro-splitting of water. Nature Materials, 11, 802- 807 (2012). https://doi.org/10.1038/nmat3385

[4] Chen W., Qu Y., Yao L., Hou X., Shi X., Pan H.: Electronic, magnetic, catalytic, and electrochemical properties of two-dimensional Janus transition metal chalcogenides. Journal of Materials Chemistry A, 6, 80218029 (2018). https://doi.org/10.1039/c8ta01202d

[5] Geng Y., Zhang P., Wang Q., Liu Y., Pan K.: Novel PAN/PVP Janus ultrafine fiber membrane and its application for biphasic drug release. Journal of Materials Chemistry B, 5, 5390-5396 (2017). https://doi.org/10.1039/C7TB00929A 
[6] Lv N., Wang Z., Bi W., Li G., Zhang J., Ni J.: C 8 -modified $\mathrm{CeO}_{2} / / \mathrm{SiO}_{2}$ Janus fibers for selective capture and individual MS detection of low-abundance peptides and phosphopeptides. Journal of Materials Chemistry B, 4, 4402-4409 (2016).

https://doi.org/10.1039/c6tb00476h

[7] Meng N., Lian F., Li Y., Zhao X., Zhang L., Lu S., Li H.: Exploring PVFM-based Janus membrane-supporting gel polymer electrolyte for highly durable $\mathrm{Li}-\mathrm{O}_{2}$ batteries. ACS Applied Materials and Interfaces, 10, 22237-22247 (2018).

https://doi.org/10.1021/acsami.8b05393

[8] Bai J., Shi Z., Yin J., Tian M., Qu R.: Shape reconfiguration of a biomimetic elastic membrane with a switchable Janus structure. Advanced Functional Materials, 28, 1800939/1-1800939/9 (2018).

https://doi.org/10.1002/adfm.201800939

[9] Zhou H., Zhang M., Li C., Gao C., Zheng Y.: Excellent fog-droplets collector via integrative Janus membrane and conical spine with micro/nanostructures. Small, 14, 201801335/1-201801335/7 (2018).

https://doi.org/10.1002/smll.201801335

[10] Yang H-C., Hou J., Chen V., Xu Z-K.: Janus membranes: Exploring duality for advanced separation. Angewandte Chemie International Edition, 55, 13398-13407 (2016).

https://doi.org/10.1002/anie.201601589

[11] Xiong Q-L., Zhou J., Zhang J., Kitamura T., Li Z-H.: Spontaneous curling of freestanding Janus monolayer transition-Metal dichalcogenides. Physical Chemistry Chemical Physics, 20, 20988-20995 (2018).

https://doi.org/10.1039/c8cp02011f

[12] Wang Z., Ma Q., Dong X., Li D., Xi X., Yu W., Wang J., Liu G.: Novel electrospun dual-layered composite nanofibrous membrane endowed with electricity-magnetism bifunctionality at one layer and photoluminescence at the other layer. ACS Applied Materials and Interfaces, 8, 26226-26234 (2016). https://doi.org/10.1021/acsami.6b08522

[13] Ma Q., Wang J., Dong X., Yu W., Liu G.: Flexible Janus nanoribbons array: A new strategy to achieve excellent electrically conductive anisotropy, magnetism, and photoluminescence. Advanced Functional Materials, 25, 2436-2443 (2015).

https://doi.org/10.1002/adfm.201500348

[14] Ma Q., Yu W., Dong X., Yang M., Wang J., Liu G.: Flexible tricolor flag-liked microribbons array with enhanced conductive anisotropy and multifunctionality. Scientific Reports, 5, 14583/1-14583/8 (2015).

https://doi.org/10.1038/srep14583

[15] Shi Y-D., Yu H-O., Li J., Tan Y-J., Chen Y-F., Wang M., Wu H., Guo S.: Low magnetic field-induced alignment of nickel particles in segregated poly(L-lactide)/poly( $\varepsilon$ caprolactone)/multi-walled carbon nanotube nanocomposites: Towards remarkable and tunable conductive anisotropy. Chemical Engineering Journal, 347, 472482 (2018).

https://doi.org/10.1016/j.cej.2018.04.147
[16] Meng L., Bian R., Guo C., Xu B., Liu H., Jiang L.: Aligning Ag nanowires by a facile bioinspired directional liquid transfer: Toward anisotropic flexible conductive electrodes. Advanced Materials, 30, 1706938/11706938/9 (2018). https://doi.org/10.1002/adma.201706938

[17] Li X., Cai J., Shi Y., Yue Y., Zhang D.: Remarkable conductive anisotropy of metallic microcoil/PDMS composites made by electric field induced alignment. ACS Applied Materials and Interfaces, 9, 1593-1601 (2016). https://doi.org/10.1021/acsami.6b13505

[18] Hamedi M. M., Hajian A., Fall A. B., Håkansson K., Salajkova M., Lundell F., Wågberg L., Berglund L. A.: Highly conducting, strong nanocomposites based on nanocellulose-assisted aqueous dispersions of singlewall carbon nanotubes. ACS Nano, 8, 2467-2476 (2014). https://doi.org/10.1021/nn4060368

[19] Liu M., Du Y., Miao Y-E., Ding Q., He S., Tjiu W. W., Pan J., Liu T.: Anisotropic conductive films based on highly aligned polyimide fibers containing hybrid materials of graphene nanoribbons and carbon nanotubes. Nanoscale, 7, 1037-1046 (2015).

https://doi.org/10.1039/c4nr06117a

[20] Mao C., Huang J., Zhu Y., Jiang W., Tang Q., Ma X.: Tailored parallel graphene stripes in plastic film with conductive anisotropy by shear-induced self-assembly. The Journal of Physical Chemistry Letters, 4, 43-47 (2013). https://doi.org/10.1021/jz301811b

[21] Lee W., Kim D., Lim J., Kim G., Kim I., Kim S., Kim J.: Light-induced electrical switch via photo-responsive nanocomposite film. Sensors and Actuators B: Chemical, 266, 724-729 (2018). https://doi.org/10.1016/j.snb.2018.03.166

[22] Rezaei B., Shoushtari A. M., Rabiee M., Uzun L., Turner A. P. F., Mak W. C.: Electrochemical performance of nanofibrous highly flexible electrodes enhanced by different structural configurations. Composites Science and Technology, 155, 81-90 (2018). https://doi.org/10.1016/j.compscitech.2017.11.031

[23] Song J. H., Kim Y-T., Cho S., Song W-J., Moon S., Park C-G., Park S., Myong J. M., Jeong U.: Surface-embedded stretchable electrodes by direct printing and their uses to fabricate ultrathin vibration sensors and circuits for 3D structures. Advanced Materials, 29, 1702625/11702625/7 (2017). https://doi.org/10.1002/adma.201702625

[24] Cabañas-Tay S. A., Palacios-Huerta L., Aceves-Mijares M., Alvarez-Quintana J., Pérez-García S. A., Domínguez-Horna C., Morales-Sánchez A.: Influence of the gate and dielectric thickness on the electro-optical performance of SRO-based LECs: Resistive switching, IR and deep UV emission. Journal of Luminescence, 192, 919-924 (2017). https://doi.org/10.1016/j.jlumin.2017.08.034 
[25] Tang Q., Fang L., Wang Y., Zou M., Guo W.: Anisotropic flexible transparent films from remaining wood microstructures for screen protection and $\mathrm{AgNW}$ conductive substrate. Nanoscale, 10, 4344-4353 (2018). https://doi.org/10.1039/c7nr08367j

[26] Chen X., Deng X., Kim N. Y., Wang Y., Huang Y., Peng L., Huang M., Zhang X., Chen X., Luo D., Wang B., Wu X., Ma Y., Lee Z., Ruoff R. S.: Graphitization of graphene oxide films under pressure. Carbon, 132, 294 303 (2018).

https://doi.org/10.1016/j.carbon.2018.02.049

[27] Wang M-H., Ji B-W., Gu X-W., Guo Z-J., Wang X-L., Yang B., Li C-Y., Liu J-Q.: A novel assembly method for 3-dimensional microelectrode array with microdrive. Sensors and Actuators B: Chemical, 264, 100 109 (2018).

https://doi.org/10.1016/j.snb.2018.02.147

[28] Luo C., Wang X., Wang J., Pan K.: One-pot preparation of polyimide $/ \mathrm{Fe}_{3} \mathrm{O}_{4}$ magnetic nanofibers with solvent resistant properties. Composites Science and Technology, 133, 97-103 (2016).

https://doi.org/10.1016/j.compscitech.2016.07.021

[29] Lv N., Zhang J. L., Li G. M., Wang X., Ni J. Z.: Novel strategy for facile synthesis of $\mathrm{C}$-shaped $\mathrm{CeO}_{2}$ nanotubes with enhanced catalytic properties. Journal of Materials Chemistry C, 121, 11926-11931 (2017). https://doi.org/10.1021/acs.jpcc.7b02967

[30] Yang S., Shao C., Li X., Zhou X., Li X., Zhang J., Tao R., Liu Y.: Molybdenum diselenide nanosheet/carbon nanofiber heterojunctions: Controllable fabrication and enhanced photocatalytic properties with a broad-spectrum response from visible to infrared light. Journal of Colloid and Interface Science, 518, 1-10 (2018). https://doi.org/10.1016/j.jcis.2018.01.099

[31] Miao F., Shao C., Li X., Wang K., Lu N., Liu Y.: Electrospun carbon nanofibers/carbon nanotubes/polyaniline ternary composites with enhanced electrochemical performance for flexible solid-state supercapacitors. ACS Sustainable Chemistry and Engineering, 4, 1689 1696 (2016). https://doi.org/10.1021/acssuschemeng.5b01631

[32] Chi M., Chen S., Zhong M., Wang C., Lu X.: Self-templated fabrication of $\mathrm{FeMnO}_{3}$ nanoparticle-filled polypyrrole nanotubes for peroxidase mimicking with a synergistic effect and their sensitive colorimetric detection of glutathione. Chemical Communications, 54, 58275830 (2018).

https://doi.org/10.1039/c8cc01574k

[33] Tian D., Lu X., Nie G., Gao M., Wang C.: Direct growth of $\mathrm{Ni}-\mathrm{Mn}-\mathrm{O}$ nanosheets on flexible electrospun carbon nanofibers for high performance supercapacitor applications. Inorganic Chemistry Frontiers, 5, 635-642 (2018).

https://doi.org/10.1039/c7qi00696a
[34] Lu X., Wang C., Favier F., Pinna N.: Electrospun nanomaterials for supercapacitor electrodes: Designed architectures and electrochemical performance. Advanced Energy Material, 7, 1601301/1-1601301/43 (2017). https://doi.org/10.1002/aenm.201601301

[35] Hou Z., Li G., Lian H., Lin J.: One-dimensional luminescent materials derived from the electrospinning process: Preparation, characteristics and application. Journal of Materials Chemistry, 22, 5254-5276 (2012). https://doi.org/10.1039/c2jm15638e

[36] Yu D-G., Yang C., Jin M., Williams G. R., Zou H., Wang X., Bligh S. W. A.: Medicated Janus fibers fabricated using a Teflon-coated side-by-side spinneret. Colloids and surfaces B: Biointerfaces, 138, 110-116 (2015). https://doi.org/10.1016/j.colsurfb.2015.11.055

[37] Yu D-G., Li J-J., Zhang M., Williams G. R.: High-quality Janus nanofibers prepared using three-fluid electrospinning. Chemical Communications, 53, 4542-4545 (2017).

https://doi.org/10.1039/C7CC01661A

[38] Wang K., Liu X-K., Chen X-H., Yu D-G., Yang Y-Y., Liu P.: Electrospun hydrophilic Janus nanocomposites for the rapid onset of therapeutic action of helicid. ACS Applied Materials and Interfaces, 10, 2859-2867 (2018). https://doi.org/10.1021/acsami.7b17663

[39] Jishkariani D., Wu Y., Wang D., Liu Y., van Blaaderen A., Murray C. B.: Preparation and self-assembly of dendronized Janus $\mathrm{Fe}_{3} \mathrm{O}_{4}-\mathrm{Pt}$ and $\mathrm{Fe}_{3} \mathrm{O}_{4}-\mathrm{Au}$ heterodimers. ACS Nano, 11, 7958-7966 (2017). https://doi.org/10.1021/acsnano.7b02485

[40] Qiu N., Liu Y., Xiang M., Lu X., Yang Q., Guo R.: A facile and stable colorimetric sensor based on three-dimensional graphene/mesoporous $\mathrm{Fe}_{3} \mathrm{O}_{4}$ nanohybrid for highly sensitive and selective detection of $p$-nitrophenol. Sensors and Actuators B: Chemical, 266, 86-94 (2018).

https://doi.org/10.1016/j.snb.2018.03.059

[41] Guo Y., Li L., Zhao C., Song L. Y., Wang B.: Humidity sensing properties of poly-vanadium-titanium acid combined with polyaniline grown in situ by electrochemical polymerization. Sensors and Actuators B Chemical 270, 80-88 (2018).

https://doi.org/10.1016/j.snb.2018.05.010

[42] Cui W., He J., Wang H., Hu J., Liu L., Liang Y.: Polyaniline hybridization promotes photo-electro-catalytic removal of organic contaminants over 3D network structure of $\mathrm{rGH}-\mathrm{PANI} / \mathrm{TiO}_{2}$ hydrogel. Applied Catalysis B: Environmental, 232, 232-245 (2018). https://doi.org/10.1016/j.apcatb.2018.03.069

[43] Hsu C-C., Lin S-L., Chang C. A.: Lanthanide-doped core-shell-shell nanocomposite for dual photodynamic therapy and luminescence imaging by a single X-ray excitation source. ACS Applied Materials and Interfaces, 10, 7859-7870 (2018). https://doi.org/10.1021/acsami.8b00015 
[44] Pedroso C. C., Carvalho J. M., Rodrigues L. C., Hölsä J., Brito H. F.: Rapid and energy-saving microwave-assisted solid-state synthesis of $\mathrm{Pr}^{3+}-, \mathrm{Eu}^{3+}$, or $\mathrm{Tb}^{3+}-$ doped $\mathrm{Lu}_{2} \mathrm{O}_{3}$ persistent luminescence materials. ACS Applied Materials andInterfaces, 8, 19593-19604 (2016).

https://doi.org/10.1021/acsami.6b04683

[45] Qin S-J., Yan B.: The point-of-care colorimetric detection of the biomarker of phenylamine in the human urine based on $\mathrm{Tb}^{3+}$ functionalized metal-organic framework. Analytica Chimica Acta, 1012, 82-89 (2018). https://doi.org/10.1016/j.aca.2018.01.041

[46] Xi X., Ma Q., Dong X., Li D., Yu W., Wang J., Liu G.: Flexible special-structured Janus nanofiber synchronously endued with tunable trifunctionality of enhanced photoluminescence, electrical conductivity and superparamagnetism. Journal of Materials Science: Materials in Electronics, 29, 7119-7129 (2018).

https://doi.org/10.1007/s10854-018-8700-5
[47] Xi X., Wang J., Dong X., Ma Q., Yu W., Liu G.: Flexible Janus nanofiber: A new tactics to realize tunable and enhanced magnetic-luminescent bifunction. Chemical Engineering Journal, 254, 259-267 (2014). https://doi.org/10.1016/j.cej.2014.05.142

[48] Ma Q., Yu W., Dong X., Wang J., Liu G.: Janus nanobelts: Fabrication, structure and enhanced magneticfluorescent bifunctional performance. Nanoscale, 6, 2945-2952 (2014). https://doi.org/10.1039/C3NR05472A

[49] Liu Y., Ma Q., Yang M., Dong X., Yang Y., Wang J., Yu W., Liu G.: Flexible hollow nanofibers: Novel one-pot electrospinning construction, structure and tunable luminescence-electricity-magnetism trifunctionality. Chemical Engineering Journal, 284, 831-840 (2016). https://doi.org/10.1016/j.cej.2015.09.030

[50] Li X., Ma Q., Tian J., Xi X., Li D., Dong X., Yu W., Wang X., Wang J., Liu G.: Double anisotropic electrically conductive flexible Janus-typed membranes. Nanoscale, 9, 18918-18930 (2017). https://doi.org/10.1039/C7NR06456J 